\title{
Influence of Gravity on Molten Pool Behavior and Analysis of Microstructure on Various Welding Positions in Pulsed Gas Metal Arc Welding
}

\author{
Jin-Hyeong Park ${ }^{1}$, Sung-Hwan Kim ${ }^{1}$, Hyeong-Soon Moon ${ }^{1, *}$ and Myung-Hyun Kim ${ }^{2, *}$ \\ 1 Precision Manufacturing \& Control R\&D Group, Korea Institute of Industrial Technology, Busan 46938, \\ Korea; parkwlsgud@kitech.re.kr (J.-H.P.); dashwan@kitech.re.kr (S.-H.K.) \\ 2 Dept. of Naval Architecture and Ocean Engineering Pusan National University, 2, Busan daehak-ro 63beon \\ gil, Geumjeong-gu, Busan 46241, Korea \\ * Correspondence: hsmoon@kitech.re.kr (H.-S.M.); kimm@pusan.ac.kr (M.-H.K.)
}

Received: 10 September 2019; Accepted: 30 October 2019; Published: 31 October 2019

\begin{abstract}
This study performed welding on various welding positions in the flat, overhead, and vertical down positions using a pulsed gas metal arc welding (P-GMAW) process. Despite the same amount of heat input on various welding positions, the welding characteristics varied depending on the welding positions. The effect of gravity on the welding process determined the different formation of the weld bead, and the influence of molten pool behavior on various welding positions changed the microstructure in the weld metal. The current and voltage signals were synchronized with a high-speed camera using a data acquisition (DAQ) system. To induce the one pulse one drop (OPOD) process of metal transfer, the shielding gas was used $95 \% \mathrm{Ar}+5 \% \mathrm{CO} 2$. The microstructure of the weld metal was analyzed in relation to molten pool behavior.
\end{abstract}

Keywords: various welding positions; molten pool behavior; one pulse one drop; microstructure

\section{Introduction}

Kumar et al. [1] and Kim et al. [2] found that pulsed gas metal arc welding (P-GMAW) decreased the spatter and reduced the occurrence of incomplete fusion defects while providing a lower heat input and achieving high penetration. The P-GMAW process incorporated the benefits of axial spray transfer of one pulse one drop (OPOD) of GMAW, which improve the stability and quality of the welding process. A significant effort was made to analyze the effect of pulsing parameters on the metal transfer behaviors and optimize the pulsing parameters to achieve the desirable metal transfer mode of OPOD [3,4].

The heat transfer and fluid flow of a molten pool can significantly influence properties such as weld pool geometry, temperature gradients, local cooling rates, and solidification structure. The driving forces for fluid flow in weld pools include the buoyancy force, electromagnetic force, surface tension gradient at the molten pool surface, and the impinging force of the arc plasma [5].

The observation of molten pool behavior presents an effective way to understand how to control the welding process and obtain valuable information for the formation of weld bead shape, which helps in the evaluation of welding quality. Extensive research has been conducted with the aim of monitoring the weld pool in arc welding [6-8]. Nagarajan et al. [9] correlated the weld penetration, weld bead width, and weld torch position using infrared images. Carlson and Johnson [10] used ultrasonic signals to estimate sidewall penetration. Wang [11] reviewed the use of three-dimensional weld pool measurements. The 3D vision sensing system was proposed in order to measure the specular 3D weld pool in gas tungsten arc welding (GTAW), and Zhang et al. [12] measured 3D weld pool surface 
with weld joint penetration. Liu et al. [13] developed a neuro-fuzzy inference system based on three characteristic parameters for observation of the molten pool.

Gravity influences the performance of welding, which affects molten pool behavior; hence, it is necessary to understand the gravity effect on weld pool convection, weld pool dimensions, microstructure evolution, and mechanical properties of the weld structure. Wang and Tandon [14] accomplished laser welding on 316 stainless steel in a simulated space environment. They determined that wide bead width and deep penetration were obtained in an environment with reduced gravity force. They also noticed an increase in porosity and suspended weld particles in such reduced gravity force conditions that may have led to a weaker weld joint. Aidun et al. [15] studied the fusion zone shapes and profiles of weld beads in 304 stainless steel under simulated high gravity force. They found that the aspect ratio of the weld fusion zone at $5 \mathrm{G}$ is smaller than that at $1 \mathrm{G}$. Kang et al. [16] performed welds related to different gravity directions such as vertical up position, vertical down position, and flat position. They found that the vertical up position caused $21 \%$ deeper penetration than the vertical down position. Kang et al. [17] stated that the direction of gravity significantly influences the weld pool shape associated with convection flows, which affect solidification morphology and primary dendrite spacing. The knowledge of how welding process parameters affect weld bead geometry is important because it can be applied to welding processes where optimal selection of input parameters is required for high productivity. Palani et al. [18] studied the weld bead geometry of beads on plate welds deposited using the flux-cored arc welding technique and showed that the percentage of dilution slightly increased with an increased welding current. Lee et al. [19] found that for a bead on plate welds of A36 steel produced using a single-wire process, the welding current had a strong influence on the size of the heat affected zone, with the size decreasing with the increasing welding current. Shen et al. [20] looked at how cooling times relate to various weld bead characteristics, such as total molten area, boundary lengths, width-to-depth ratio, and nugget parameters, and how heat inputs affect dilution and weld melting efficiencies.

This study observed molten pool behavior and analyzed microstructures in various welding positions in P-GMAW. A high-speed camera was used for observation of the molten pool in various positions and for analysis of the phenomenon of molten pool behavior with gravity effect. In addition, a P-GMAW process experiment was performed using the same welding conditions. The welding signals in the P-GMAW process were synchronized with molten pool images. The fusion zone shapes of cross-sections were compared, and the microstructures were analyzed in various welding positions.

\section{Experimental Procedure}

\subsection{Materials and Experiment Conditions}

A single-pass bead-on-plate was performed by P-GMAW. The dimensions of the test specimen were $500 \mathrm{~mm}$ (length) $\times 100 \mathrm{~mm}$ (width) $\times 9 \mathrm{~mm}$ (thickness) and mild steel (SS400) was used as a base metal. The filler wire was ER70S-6 with a diameter of $1.0 \mathrm{~mm}$. Welding was performed in the flat, overhead, and vertical down positions, as shown in Figure 1. Table 1 summarizes the experiment conditions for various welding positions. The welding power supply used a TransPuls Synergic (TPS) 2700 welding machine, the wire feed rate (WFR) was $7 \mathrm{~m} / \mathrm{min}$, and the welding speed was $60 \mathrm{~cm} / \mathrm{min}$. The shielding gas was $95 \% \mathrm{Ar}+5 \% \mathrm{CO} 2$, and the gas flow rate was $20 \mathrm{~L} / \mathrm{min}$. The contact tip to work distance (CTWD) was $15 \mathrm{~mm}$. A $695 \mathrm{~nm}$ band pass filter was placed in front of the high-speed camera to block the intense light from the welding arc. A high-speed camera with 5000 frames per second (FPS) captured the molten pool behavior in various welding positions. The chemical composition of the filler wire and base metal is shown in Table 2. 


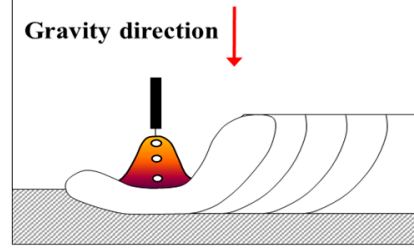

(a) Flat position

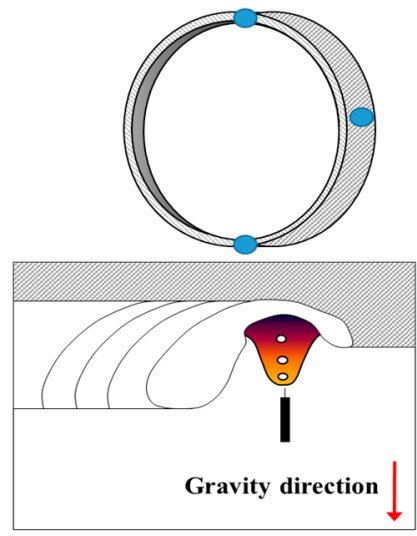

(b) Overhead position

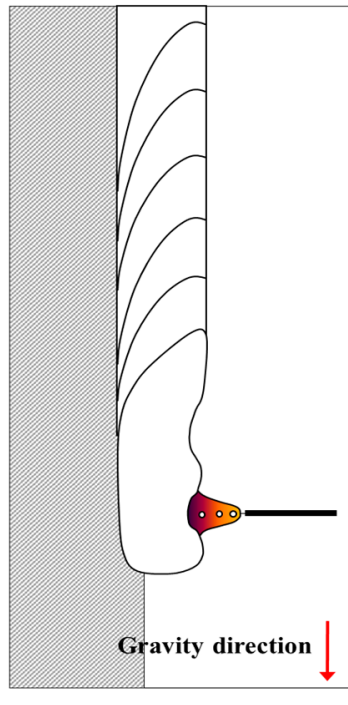

(c) Vertical down position

Figure 1. Experimental set-up for various welding positions.

Table 1. Experiment conditions.

\begin{tabular}{cc}
\hline Parameter & Conditions \\
\hline Shielding gas & $95 \% \mathrm{Ar}+5 \% \mathrm{CO} 2,20 \mathrm{~L} / \mathrm{min}$ \\
Welding travel speed & $60 \mathrm{~cm} / \mathrm{min}$ \\
Wire feed rate & $7 \mathrm{~m} / \mathrm{min}$ \\
Contact tip to work distance & $15 \mathrm{~mm}$ \\
High-speed camera & Phantom m320s, frame rate $5000 \mathrm{~Hz}$ \\
Wire & Er70s-6, $1 \mathrm{~mm}$ \\
Band pass filter & $695 \mathrm{~nm}$ \\
Welding machine & TPS-2700 \\
Peak current & $345 \mathrm{~A}$ \\
Base current & $35 \mathrm{~A}$ \\
Pulse frequency & $151.5 \mathrm{~Hz}$ \\
Pulse duration & $0.0012 \mathrm{~s}$ \\
\hline
\end{tabular}

Table 2. Chemical composition (typical).

\begin{tabular}{ccccccccc}
\hline Materials & $\mathbf{C}$ & $\mathbf{S i}$ & $\mathbf{M n}$ & $\mathbf{P}$ & $\mathbf{S}$ & $\mathbf{A l}$ & $\mathbf{C u}$ & $\mathbf{F e}$ \\
SS400 & 0.16 & 0.20 & 0.6 & 0.01 & 0.008 & 0.05 & 0.02 & Bal. \\
ER70S-6 & $0.07-0.19$ & $0.65-0.85$ & $1-1.5$ & $<0.025$ & 0.035 & $0.5-0.9$ & $>0.5$ & Bal. \\
\hline
\end{tabular}

\subsection{Welding Equipment}

For acquiring the welding signal, a voltage sensor was connected to the torch and ground position, and a current sensor was used as a Hall sensor. The signals from the two sensors were transmitted to a computer through a DAQ board. To observe the phenomenon of the real-time welding process, the high-speed camera was adjusted to synchronize with the current and voltage signals using the DAQ board. The schematic of the experiment system setup is shown in Figure 2. 


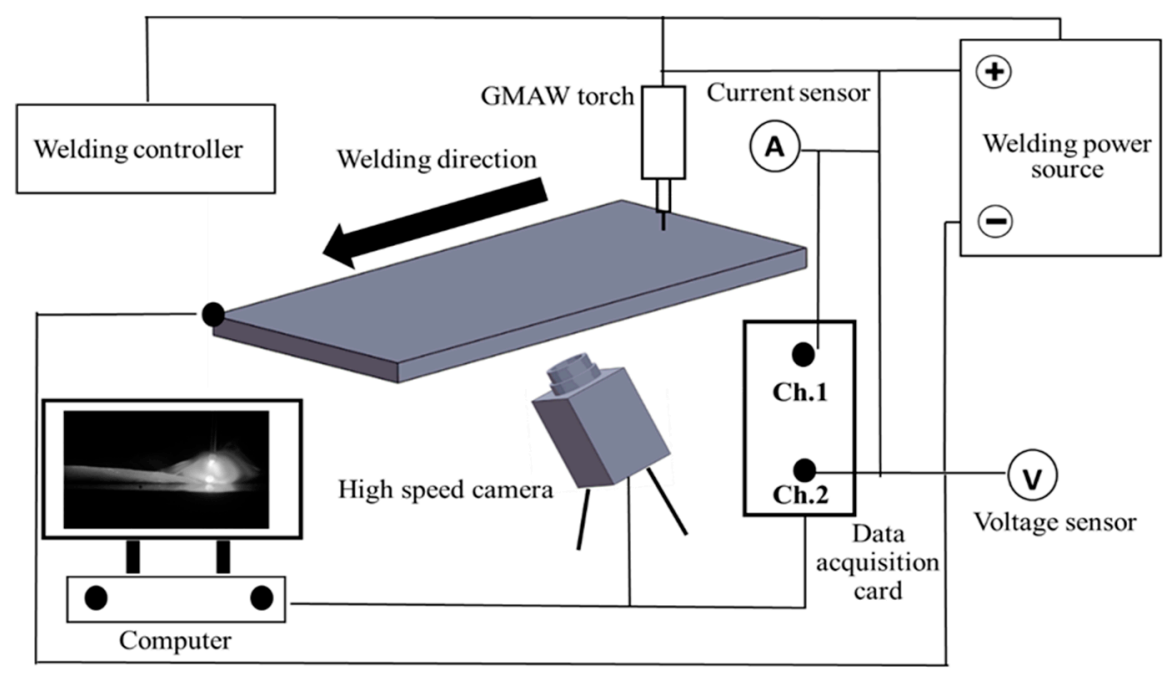

Figure 2. Schematic of the experimental setup for synchronization of arc imaging with welding signal. GMAW—gas arc metal welding.

\subsection{Preparation for Metallographic Examination}

The transverse sections of the weld metal were mechanically polished and nitric acid etching was conducted to reveal the microstructure. Metallographic analysis was carried out using a scanning electron microscope (SEM). For some selected specimens, the micro-hardness profiles across the welded plates were measured using a $0.5 \mathrm{Kg}$ test load and a dwell period of $10 \mathrm{~s}$ with a Vickers hardness machine (Shimadzu Micro Hardness Tester HMV-2).

\section{Results and Discussion}

\subsection{Flat Position}

The observation of the molten pool behavior captured the longitudinal direction with 5000 FPS. The OPOD in metal transfer for an approximately square current waveform and the molten pool behavior of OPOD in GMAW are shown in Figure 3a. It can be more clearly observed that the welding current and voltage varied with time. The dynamic molten pool images varied at a high frequency pulse period of $151.5 \mathrm{~Hz}$. The base current and the peak current were 35 and $345 \mathrm{~A}$, respectively, and the pulse duration was $0.0012 \mathrm{~s}$, as shown in Figure 3b. Cho et al. [21] confirmed that variation in the effective radius and welding signals induce different molten pool flow patterns because the smaller arc size of the arc plasma produces a higher arc force density. On the other hand, the average constant effective radius and welding signal cannot induce a deeper penetration. Hence, it is important to confirm that the OPOD transfer mode occurs in P-GMAW. The duration of the entire mechanism for detachment of a droplet from the electrode tip in the P-GMAW process primarily combines the following four stages: (1) Heating and melting are shown in Figure 3a at 3.0046 s; (2) formation and growth of droplet are shown from 3.0052 to $3.0064 \mathrm{~s}$; (3) necking at the root of the growing drop is shown from 3.007 to $3.0076 \mathrm{~s}$; and (4) detachment of the droplet is shown at $3.0082 \mathrm{~s}$. 

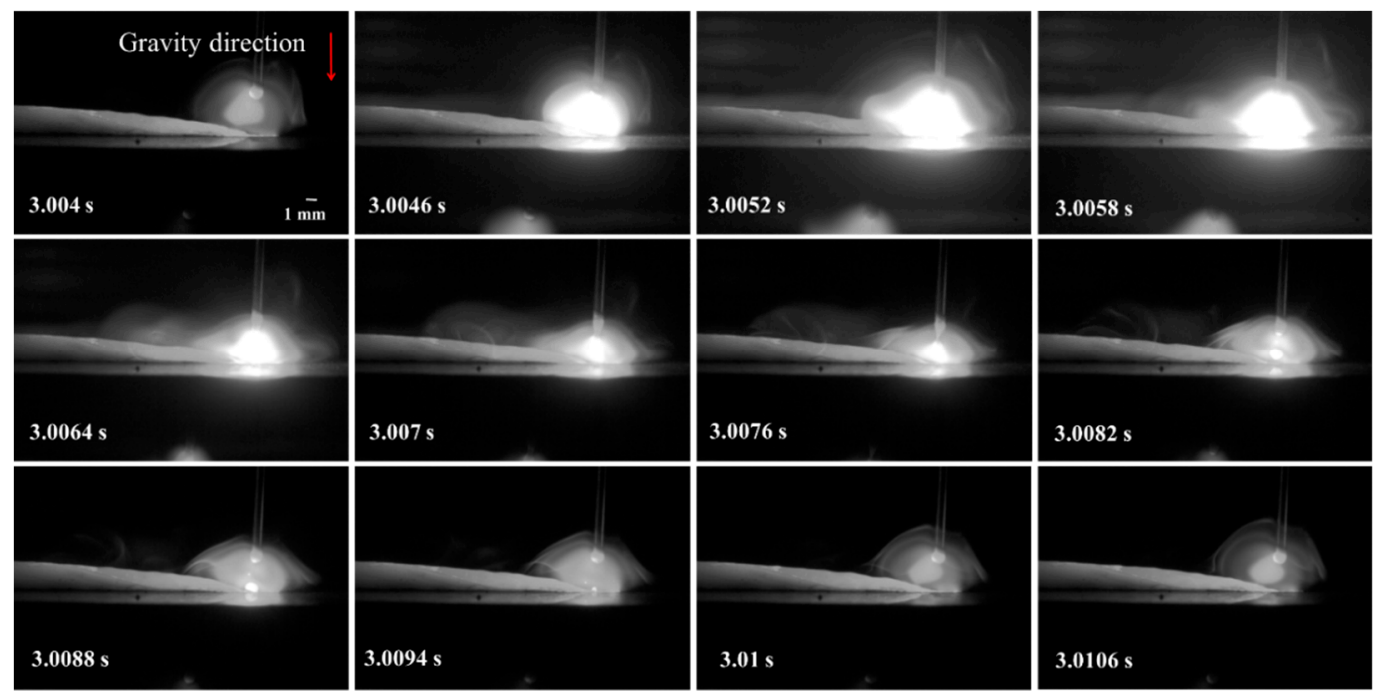

(a) Arc images

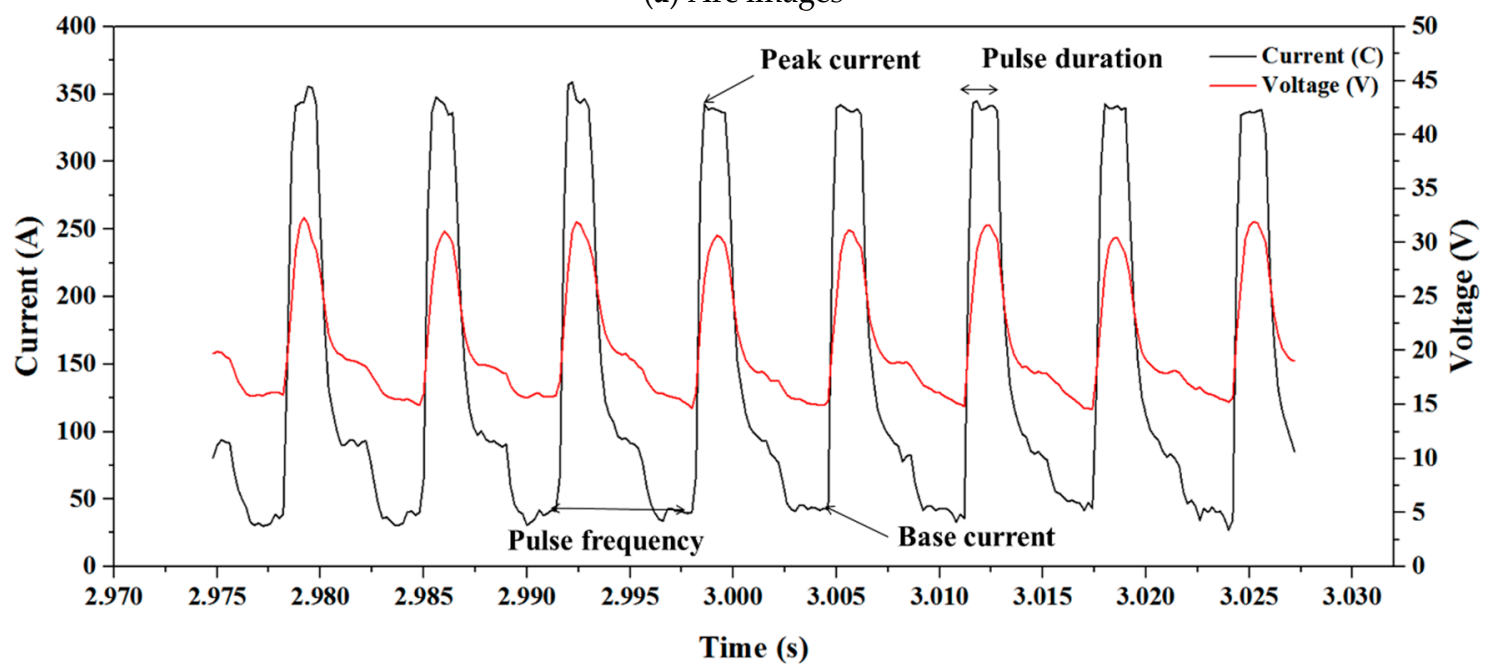

(b) Welding signals

Figure 3. Synchronization of (a) arc images and (b) welding signals with a wire feed rate (WFR) of $7 \mathrm{~m} / \mathrm{min}$.

\subsection{Overhead Position}

The observation of molten pool behavior with a longitudinal direction in the overhead position is shown in Figure 4a. The dynamic arc imaging synchronization of waveforms is shown in Figure $4 \mathrm{~b}$. In the overhead welding position, the direction of gravity is opposite to the flat position. The tail of the molten pool in the overhead position affected the strong backward flow because the reverse gravity direction combined with the backward flow. Hence, more molten metal was accumulated in the tail of the molten pool and reverse gravity extracts the molten pool into the top surface direction. These molten pool flow patterns increased the bead height as shown in Figure 5.

$\mathrm{Xu}$ et al. [22] established a unified 3D model to investigate the formation mechanism of a humping bead in high-speed GMAW and found that the strong backward fluid metal flow in the weld pool was the major reason for the humping formation. The combined effect of large arc pressure and droplet impact caused severe depression of the molten pool surface at the arc center [23]. The WFR of $9 \mathrm{~m} / \mathrm{min}$ increased the values of droplet frequency $(217.3 \mathrm{HZ}$ ) as shown in Figure 6. Increasing the droplet frequency caused more molten metal flow into the tail of the molten pool. Therefore, a strong backward flow weakens the molten pool layer in the arc center and breaks the molten pool bridge. Hence, increasing the WFR caused the humping bead formation, as shown in Figure 7. 


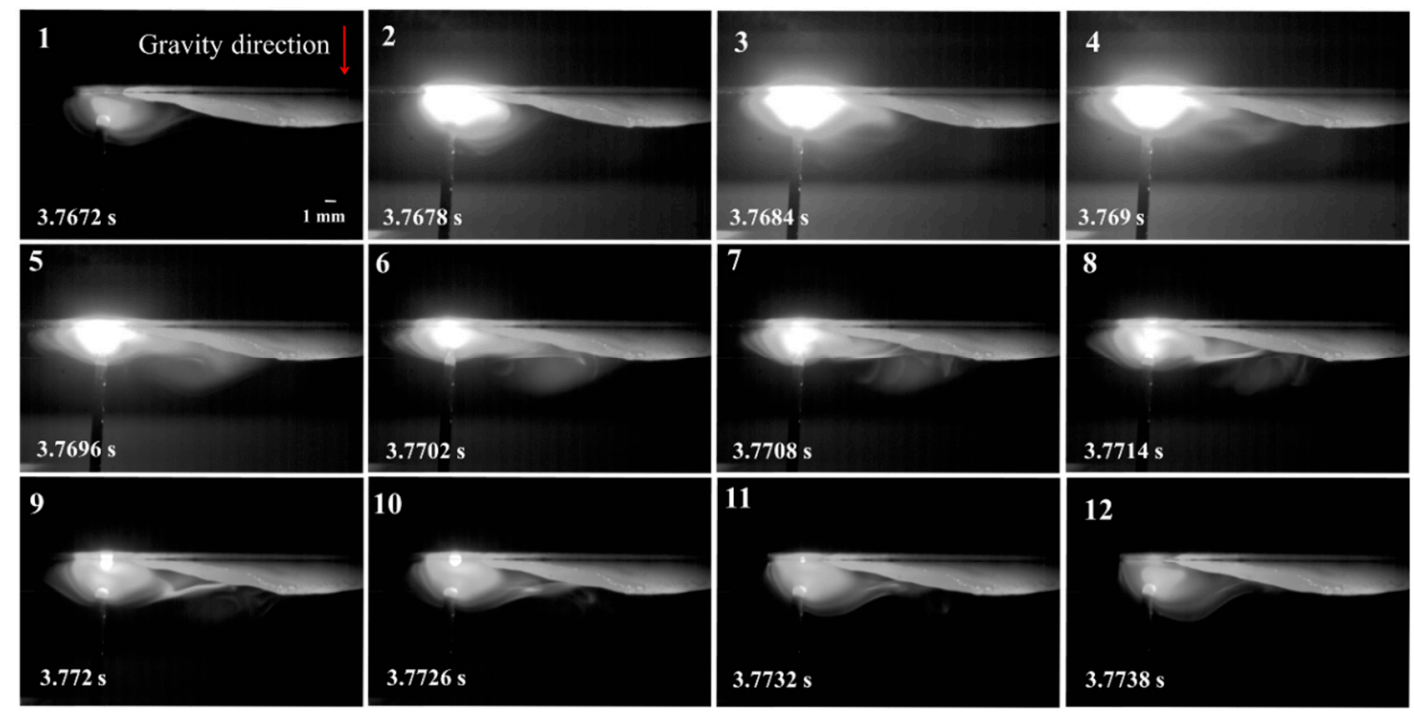

(a) Arc images

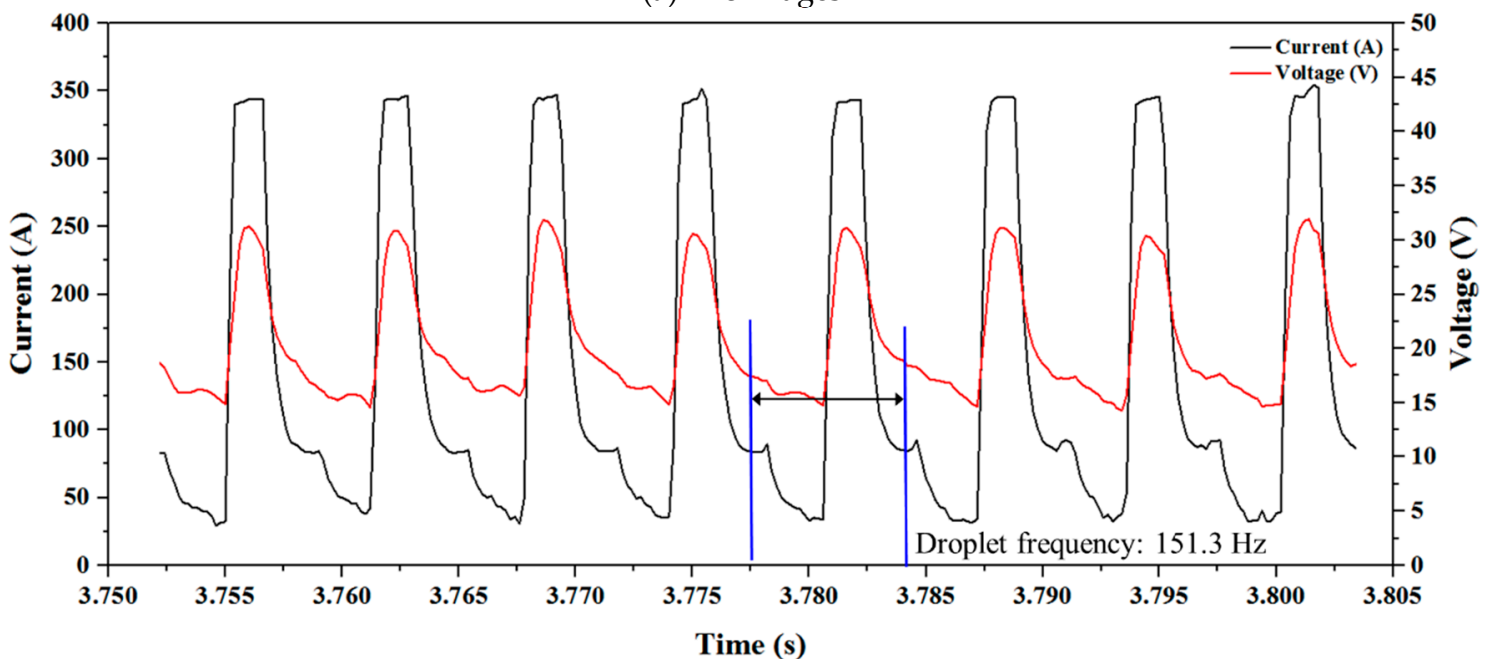

(b) Welding signals

Figure 4. Synchronization of (a) arc images and (b) welding signals at a WFR of $7 \mathrm{~m} / \mathrm{min}$.
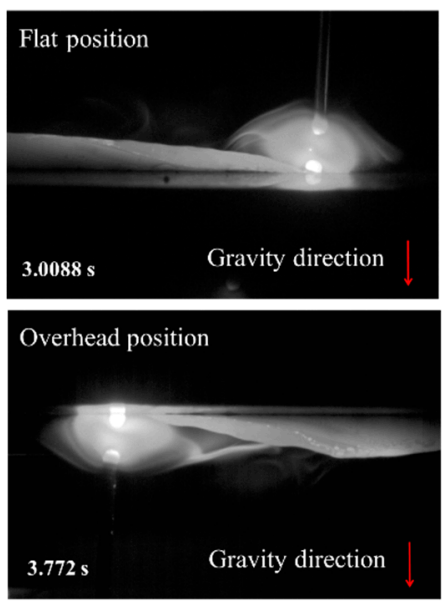
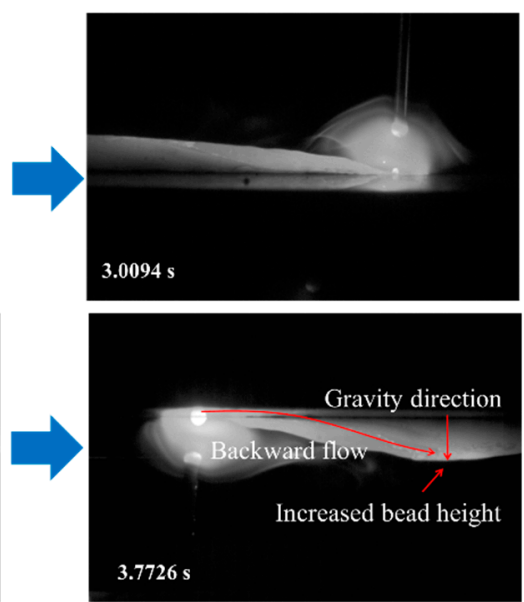
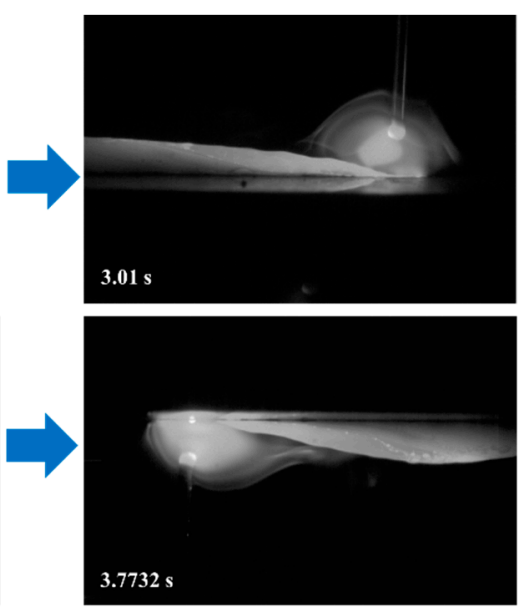

Figure 5. Characteristics of overhead welding position. 


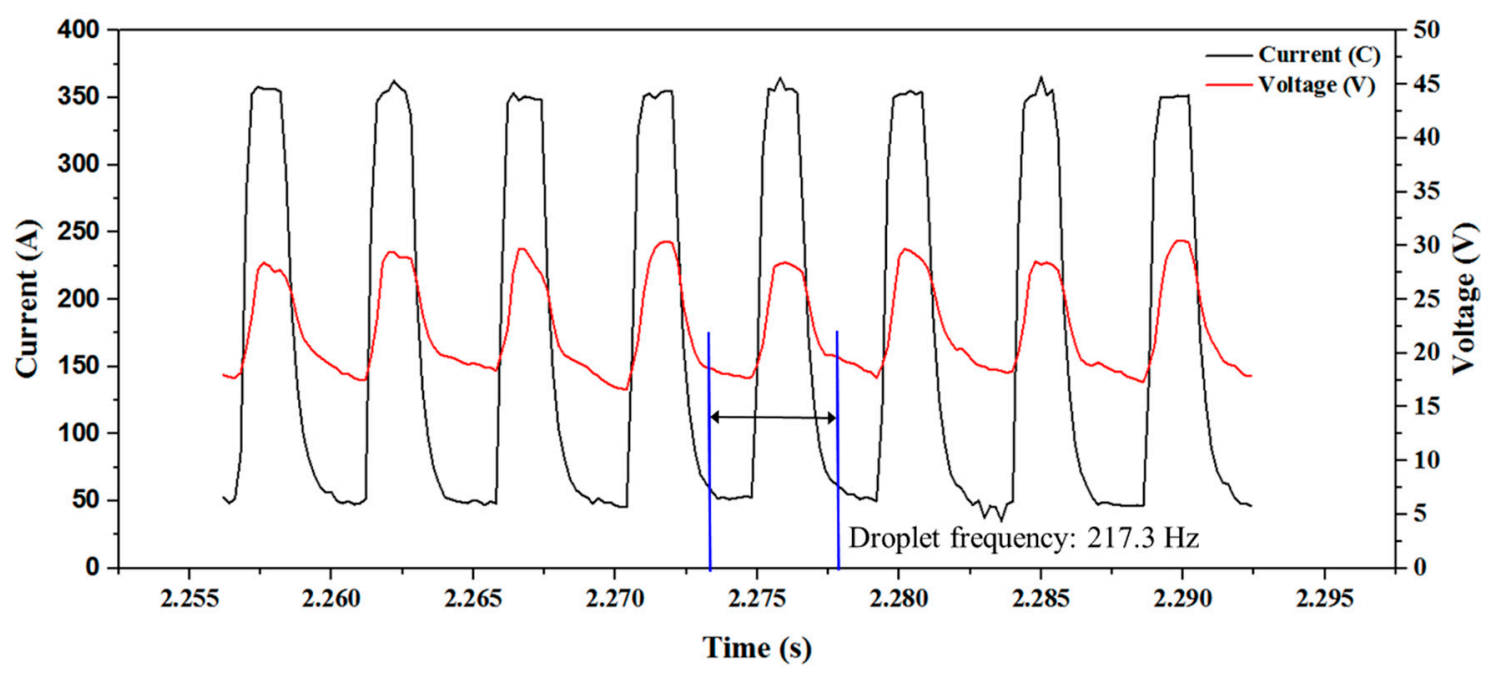

Figure 6. Welding signals with a WFR of $9 \mathrm{~m} / \mathrm{min}$.

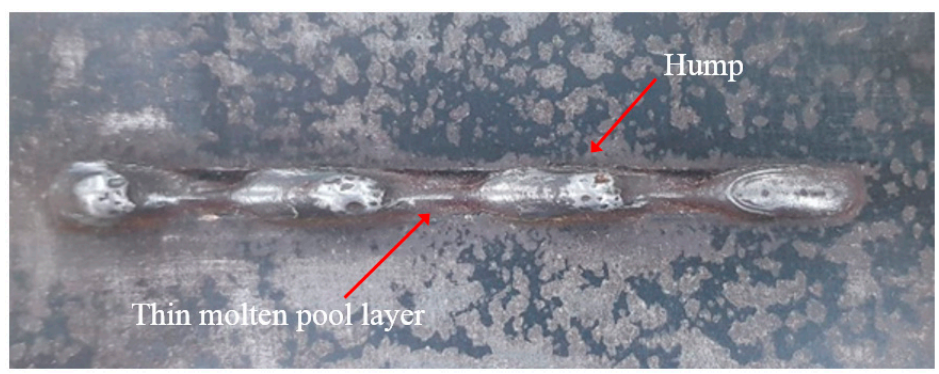

Figure 7. Formation of humping bead with a WFR of $9 \mathrm{~m} / \mathrm{min}$.

\subsection{Vertical down Position}

The observation of molten pool behavior with a longitudinal direction in the vertical down position is shown in Figure 8a. The dynamic arc imaging synchronization of waveforms is shown in Figure 8b. During the welding procedure, the gravity continuously pushed the molten pool flow forward and more molten pool piled up between the arc ignition and base metal, creating a cushion effect, as shown in Figure 9. The accumulation of the molten pool in the arc center caused the arc length to shorten close to the droplet on the molten pool surface. As a result, the short circuit transfer mode occasionally occurred when the wire contacts the surface of the molten pool before droplet detachment, as shown in Figure 10. This condition induced an unstable arc and more spatters occurred in the vertical down position. Due to the accumulated molten pool in the arc center, arc forces such as arc pressure, electromagnetic force, and droplet impact in OPOD transfer mode suppressed the surface of the molten pool. Under these conditions, the short circuit transfer and OPOD transfer obstructed the depth penetration because the accumulated molten pool prevented downward flow into the base metal. Therefore, the penetration depth had the smallest value of $0.8 \mathrm{~mm}$ and bead width had the largest value of $6.9 \mathrm{~mm}$ compared to other welding positions.

\subsection{Analysis of Microstructure and Hardness Character}

Hardness contour plots corresponding to microstructures of local location in the weld metal are shown in Figure 11. In the flat position, the microstructures in the weld metal consist of allotriomorphic acicular ferrite (AF) grains, polygonal ferrite (PF) grains, and bainite (B) in Figure 12a. In the overhead welding position, the convective heat transfer strongly flowed into the tail of the molten pool because the reversed gravity direction combined with backward flow. Hence, more molten metal piled up in the tail of the molten pool and the gravity effect extracted the molten pool into the top surface direction. These conditions delayed the molten pool solidification time or process. Therefore, the microstructures 
in the weld metal consist of allotriomorphic polygonal ferrite grains with a small amount of acicular ferrite grains in Figure 11b, and the distribution of hardness had the lowest values in the weld metal. In the vertical down position, because the gravity effect continuously pushed the molten pool into the arc center, a tail of the molten pool was caused by the rapid cooling rate. Hence, the microstructures in the weld metal mainly consist of acicular ferrite with small fractions of bainite as shown in Figure 11c and distribution of hardness had the highest values in weld metal, respectively. It was confirmed experimentally that microstructures and hardness characteristics of weld metals change according to the molten pool behavior on various welding positions in the same welding conditions. The experimental results for the cross-section of weld in various welding positions is shown in Figure 12. Table 3 summarizes the result of bead profiles in various welding positions.
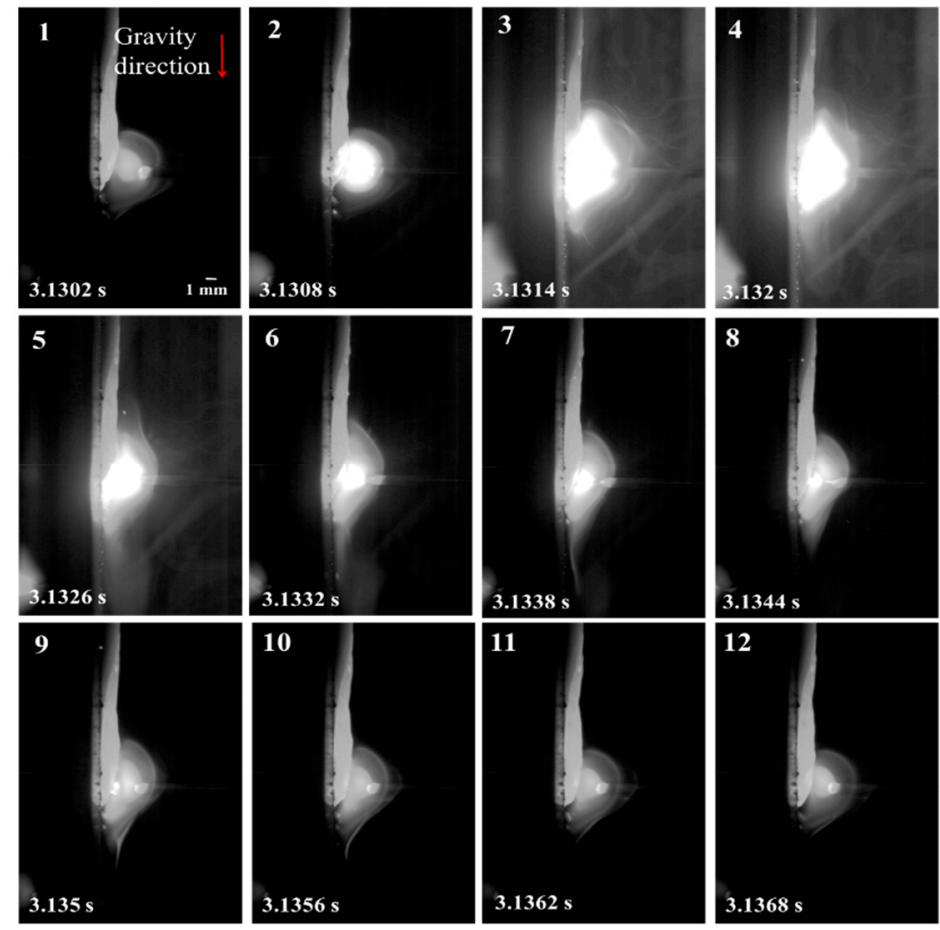

(a) Arc images

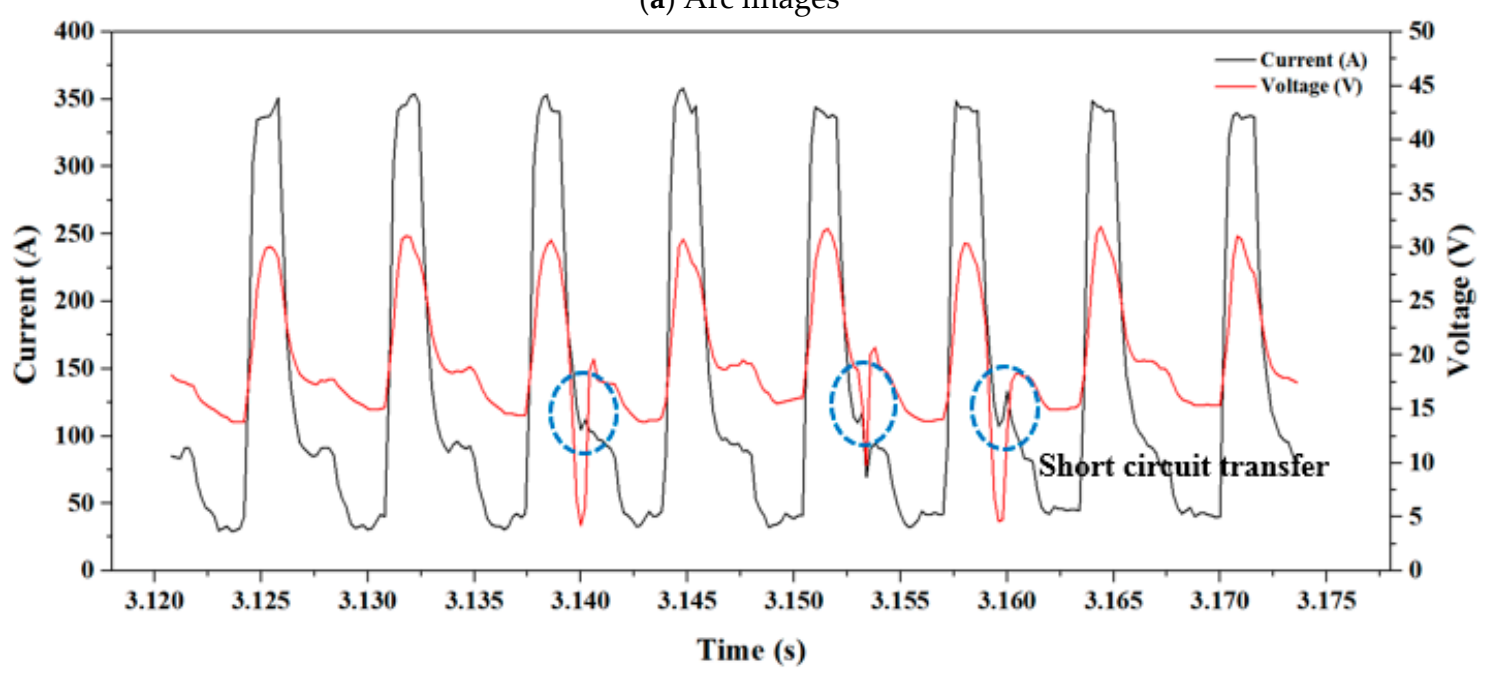

(b) Welding signals

Figure 8. Synchronization of (a) arc images and (b) welding signals in vertical down position with a WFR of $7 \mathrm{~m} / \mathrm{min}$. 


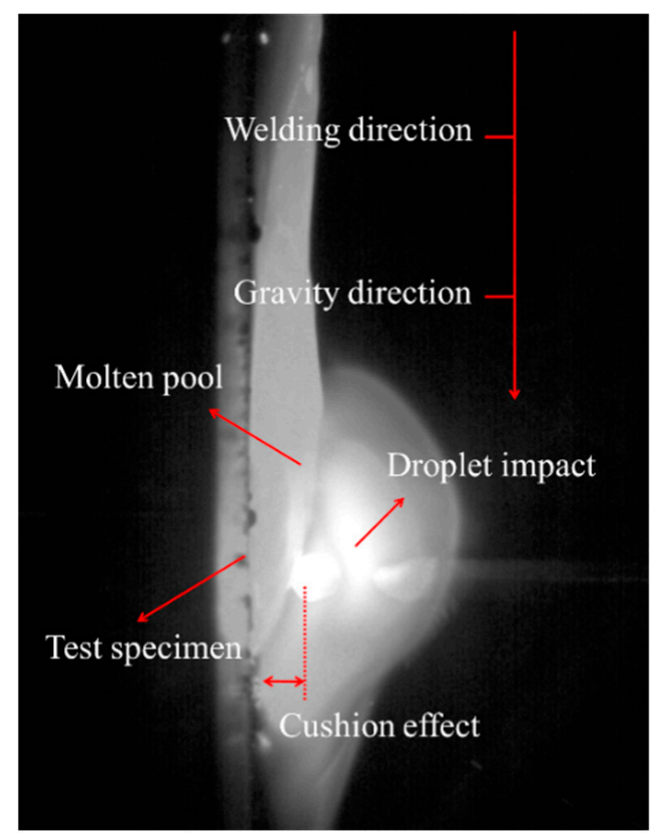

Figure 9. Cushion effect in vertical down position.
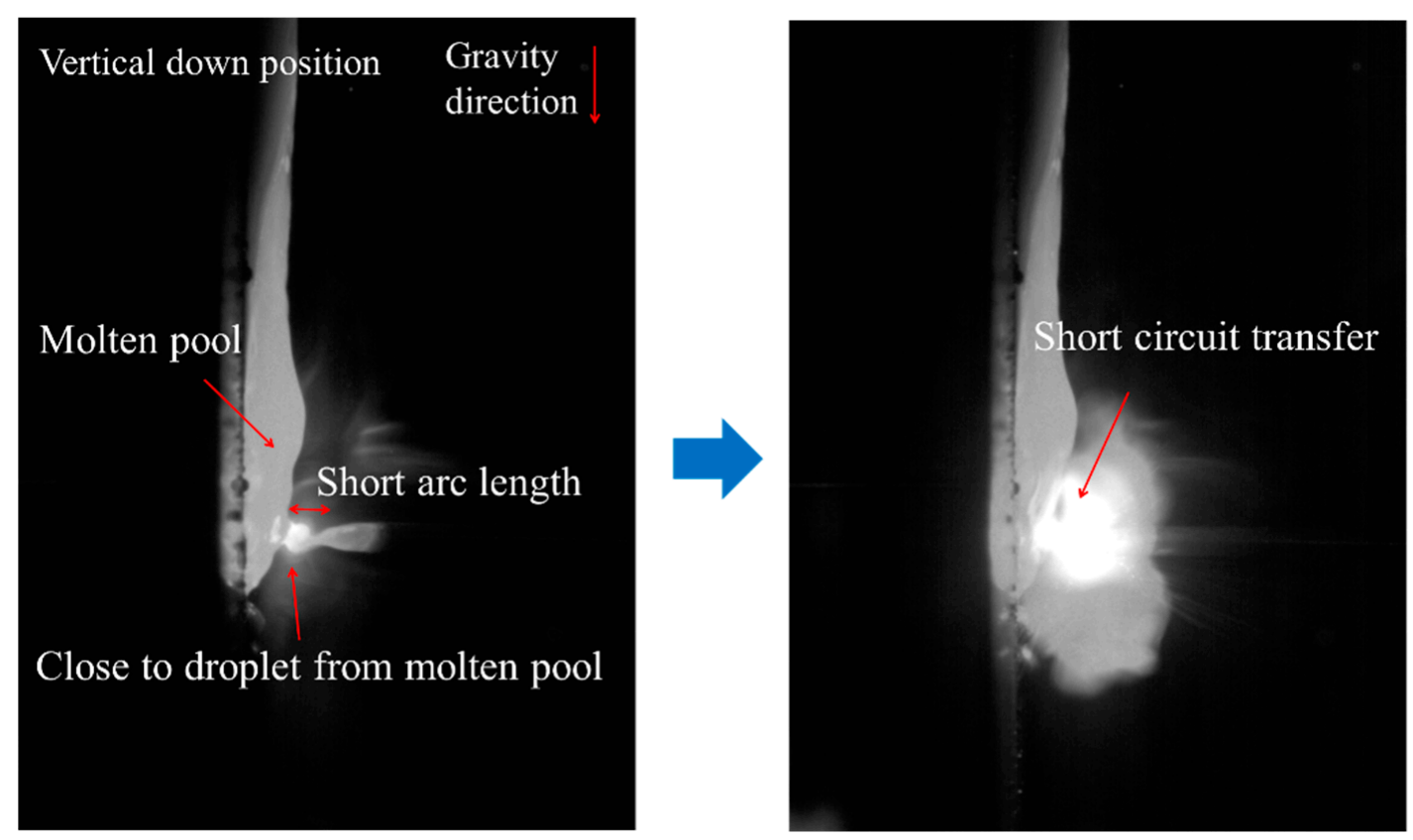

Figure 10. Short circuit transfer in vertical down position.

Table 3. Experimental results of bead profiles in various welding positions.

\begin{tabular}{cccc}
\hline Welding Position & Bead Width $(\mathbf{m m})$ & Bead Height $(\mathbf{m m})$ & Penetration $(\mathbf{m m})$ \\
\hline Flat & 6.1 & 2.2 & 1.8 \\
Overhead & 5.7 & 2.5 & 1.9 \\
Vertical down & 6.9 & 1.8 & 0.8 \\
\hline
\end{tabular}




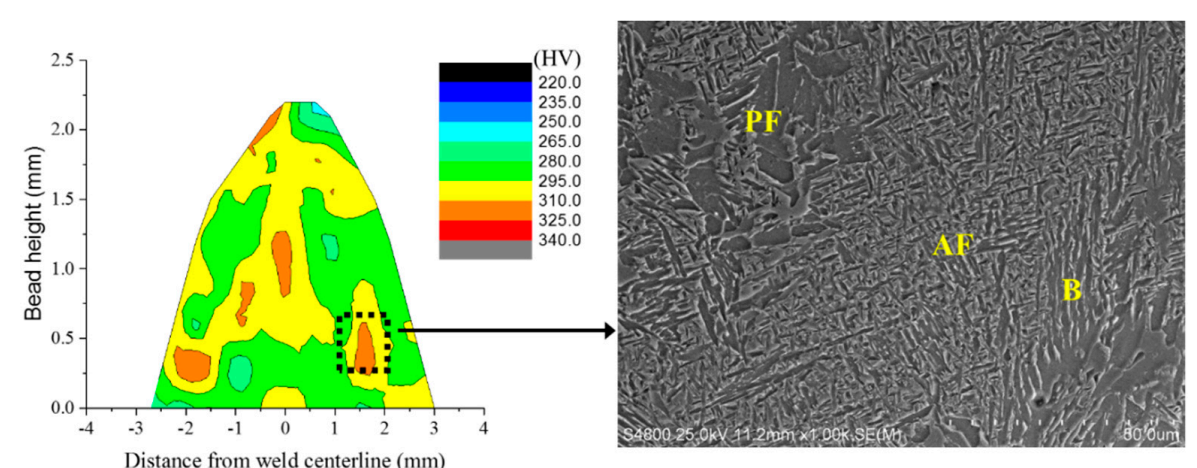

Distance from weld centerline $(\mathrm{mm})$

(a)
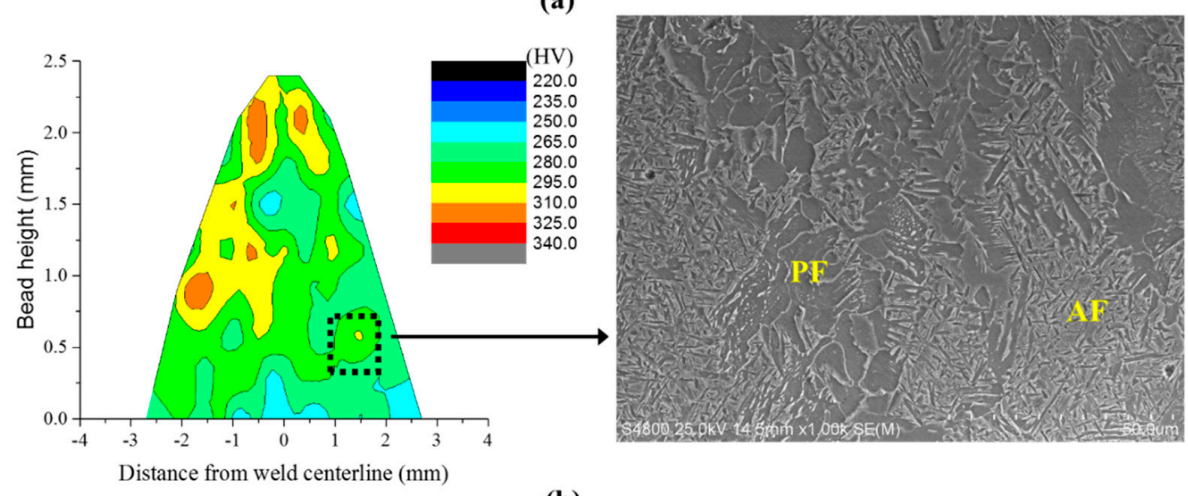

(b)
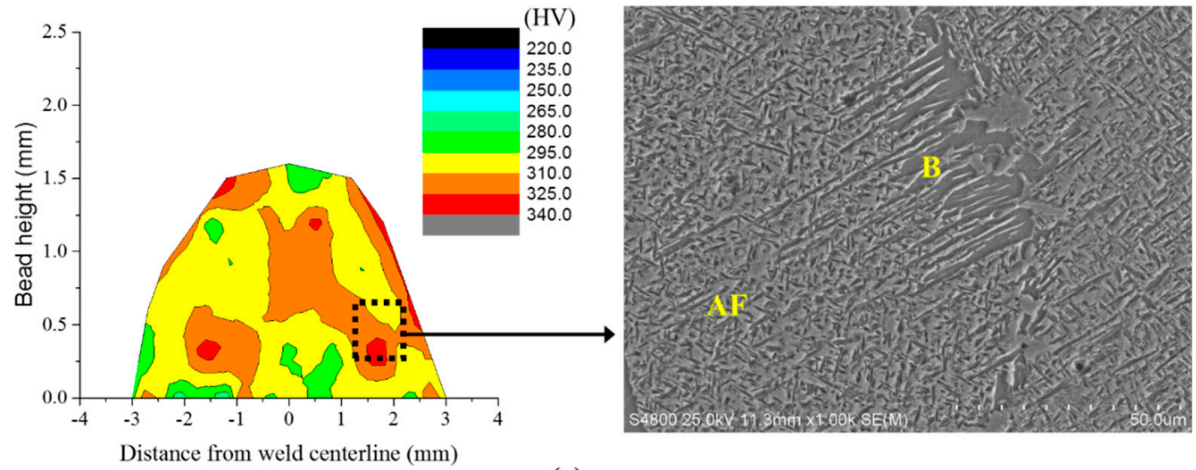

(c)

Figure 11. Hardness contour plots corresponding to microstructures in the weld metal: (a) flat position; (b) overhead position; (c) vertical down position.

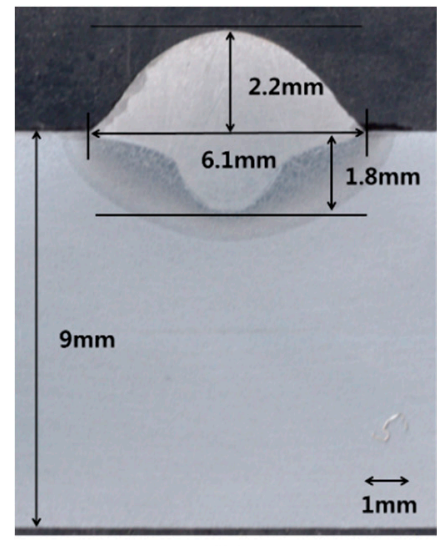

(a)

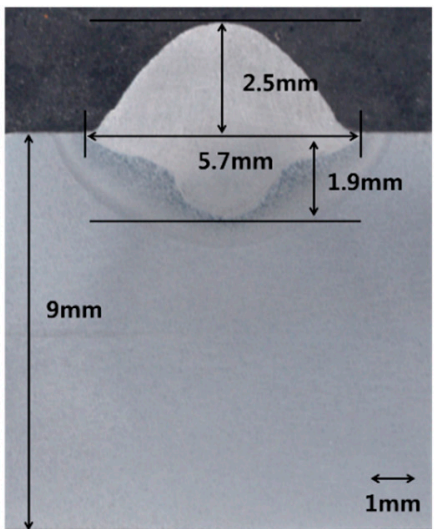

(b)

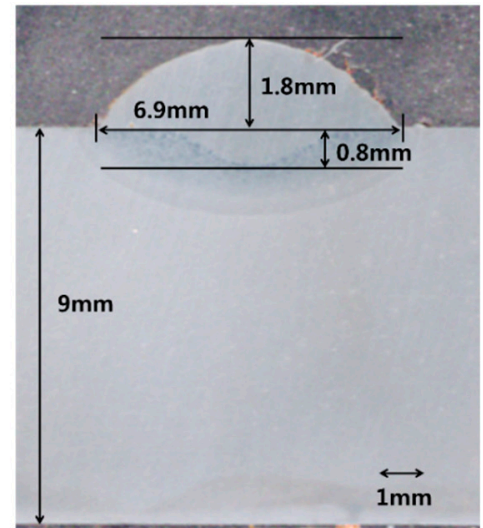

(c)

Figure 12. Experiment results of bead profiles: (a) flat position; (b) overhead position; (c) vertical down position. 


\section{Conclusion}

This paper analyzed molten pool behaviors for OPOD in the GMAW process. The effect of gravity on the molten pool influenced the weld shape and changed the microstructures in various positions. The results of this work can be summarized as follows:

(1) With a synchronized high-speed camera and DAQ system, it is possible to observe molten pool behaviors with synchronized welding signals of the OPOD transfer mode in GMAW in various positions during a real-time welding process. (2) In the overhead position, due to the reverse gravity direction combined with backward flow, the tail of the molten pool increased the bead height, which formed a convex bead shape and the microstructures mainly consisted of polygonal ferrite grains in the weld metal which slowly solidified with the cooling rate. Distribution of hardness values were lowest in the weld metal. Increasing the droplet frequency caused more molten metal flow into the tail of the molten pool. Therefore, a strong backward flow weakened the molten pool layer in the arc center, resulting in a humping bead formation.

(3) In the vertical position, accumulation of the molten pool in the arc center created a cushion effect, which reduced the depth of penetration and formed a concave bead shape. The gravity effect pushed the molten pool flow forward and a tail of the molten pool occurred with a rapid cooling rate. Microstructures mainly consisted of acicular ferrite grains. Distribution of hardness values were highest in the weld metal.

Author Contributions: Conceptualization, J.-H.P. and S.-H.K.; methodology, J.-H.P.; software, J.-H.P.; validation, J.-H.P.; formal analysis, J.-H.P.; investigation, J.-H.P.; resources, J.-H.P.; data curation, S.-H.K.; writing—original draft preparation, J.-H.P.; writing—review and editing, H.-S.M.; visualization, S.-H.K.; supervision, M.-H.K.; project administration, M.-H.K.; funding acquisition, H.-S.M.

Funding: This research received no external funding.

Conflicts of Interest: The authors declare no conflict of interest.

\section{References}

1. Kumar, R.; Dilthey, U.; Dwivedi, D.K.; Ghosh, P.K. Thin sheet welding of Al 6082 alloy by AC pulse-GMA and AC wave pulse-GMA welding. Mater. Des. 2009, 30, 306-313. [CrossRef]

2. Kim, R.H.; Choi, G.D.; Kim, C.H.; Cho, D.W.; Na, S.J. Arc characteristics in pulse-GMA welding with acute groove angles. Weld. J. 2012, 91, 101-104.

3. Zhang, Y.M.; Liguo, E.; Kovacevic, R. Active metal transfer control by monitoring excited droplet oscillation. Weld. J. 1998, 77, 388s-395s.

4. Wu, C.S.; Chen, M.A.; Li, S.K. Analysis of excited droplet oscillation and detachment in active control of metal transfer. Comput. Mater. Sci. 2004, 31, 147-154. [CrossRef]

5. Kou, S.; Sun, D.K. Fluid flow and weld penetration in stationary arc welds. Met. Trans. A 1985, 16, 203-213. [CrossRef]

6. Guokai, Z.; Chuansong, W.; Xinfeng, L. Single vision system for simultaneous observation of keyhole and weld pool in plasma arc welding. J. Mater. Process. Technol. 2015, 215, 75-78.

7. Saeed, G.; Zhang, Y.M. Weld pool surface depth measurement using a calibrated camera and structured light. Meas. Sci. Technol. 2007, 18, 2570-2578. [CrossRef]

8. Wu, C.S.; Zhong, L.M.; Gao, J.Q. Visualization of hump formation in high-speed gas metal arc welding. Meas. Sci. Technol. 2009, 20,1-8. [CrossRef]

9. Nagarajan, S.; Banerjee, P.; Chen, W.H. Control of the welding process using infrared sensors. IEEE Trans. Robot. Autom. 1992, 8, 86-93. [CrossRef]

10. Carlson, N.M.; Johnson, J.A. Ultrasonic sensing of weld pool penetration. Weld. J. 1988, 67, 47. [CrossRef]

11. Wang, X.W. Three-dimensional vision applications in GTAW process modeling and control. Int. J. Adv. Manuf. Technol. 2015, 80, 1601-1611. [CrossRef]

12. Zhang, W.J.; Liu, Y.K.; Wang, X.; Zhang, Y.M. Characterization of three dimensional weld pool surface in GTAW. Weld. J. 2012, 91, 195-203. 
13. Liu, Y.K.; Zhang, W.J.; Zhang, Y.M. Dynamic neuro-fuzzy-based human intelligence modeling and control in GTAW. IEEE Trans. Autom. Sci. Eng. 2015, 12, 324-335. [CrossRef]

14. Wang, G.; Tandon, K.N. The microstructural changes during welding of stainless steel under reduced gravity environment. Microgravity Sci. Technol. 1993, 6, 96-100.

15. Aidun, D.K.; Martin, S.; Domey, J. The effect of gravity on the weld pool shape in stainless steel. In Centrifugal Materials Processing; Regel, L.L., Wilcox, W.R., Eds.; Plenum Press: New York, NY, USA, 1997; pp. 177-182.

16. Kang, N.; Singh, J.; Kulkarni, A. Effects of gravitational orientation on the microstructural evolution of gas tungsten arc welds in an Al-4 wt\% Cu alloy. J. Mater. Sci. 2003, 38, 3579-3589. [CrossRef]

17. Kang, N.; Mahank, T.A.; Kulkarni, A.K.; Singh, J. Effects of gravitational orientation on surface deformation and weld pool geometry during gas tungsten arc welding. Mater. Manuf. Process. 2003, 18, 169-180. [CrossRef]

18. Palani, P.K.; Murugan, N. Optimization of weld bead geometry for stainless steel claddings deposited by FCAW. J. Mater. Process. Technol. 2007, 190, 291-299. [CrossRef]

19. Lee, C.S.; Chandel, R.S.; Seow, H.P. Effect of welding parameters on the size of heat affected zone of submerged arc welding. Mater. Manuf. Process. 2000, 15, 649-666. [CrossRef]

20. Shen, S.; Qguocha, I.N.A.; Yannacopoulos, S. Effect of heat input on weld bead geometry of submerged arc welded ASTM A709 Grade 50 steel joints. J. Mater. Process. Technol. 2012, 212, 289-294. [CrossRef]

21. Cho, D.W.; Park, J.H.; Moon, H.S. A study on molten pool behavior in the one pulse one drop GMAW process using computational fluid dynamics. J. Heat Mass Transf. 2019, 139, 848-859. [CrossRef]

22. Xu, G.; Cao, Q.; Hu, Q.; Zhang, W.; Liu, P.; Du, B. Modelling of bead hump formation in high speed gas metal arc welding. Sci. Technol. Weld. Join. 2016, 8, 700-710. [CrossRef]

23. Nguyen, T.C.; Weckman, D.C.; Johnson, D.A.; Kerr, H.W. The humping phenomenon during high speed gas metal arc welding. Sci. Technol. Weld. Join. 2005, 10, 447-459. [CrossRef]

(C) 2019 by the authors. Licensee MDPI, Basel, Switzerland. This article is an open access article distributed under the terms and conditions of the Creative Commons Attribution (CC BY) license (http://creativecommons.org/licenses/by/4.0/). 